\title{
OS CIGANOS ENTRE PERSEGUIÇÃO E EMANCIPAÇÃO
}

\author{
Serge Moscovici*
}

Resumo: Toda sociedade que classifica os homens e separa os grupos autóctones dos grupos "estrangeiros" inclui um sistema de crenças, religiosas ou outras. Suas representações obedecem a uma norma que dá a seus atos um sentido ético. Esses atos não são cometidos por criminosos ou loucos, mas por pessoas que sabem o que é permitido ou proibido, qual é a diferença entre o bem e o mal. O ponto de partida das reflexões apresentadas é que estereótipos - categorias discriminando grupos em brancos e negros, cristãos e judeus, franceses e alemães, indígenas e espanhóis, ciganos e romenos, etc. - constituem, em suma, um modo de conhecimento com a função de opor os "semelhantes" preferidos aos "diferentes" desprezíveis, de distinguir aqueles que não são como nós.

Palavras-chave: preconceito; ciganos; representações sociais; Psicologia Social.

Este artigo retoma e amplia algumas reflexões propostas por ocasião da Jornada Internacional sobre Representações Sociais, ocorrida em julho de 2007, em Brasília. ${ }^{1}$ A qualidade do acolhimento oferecido e das trocas então realizadas me encorajou a apresentar idéias ainda incompletas. Ouso mesmo ao luxo de improvisar algumas, cujo alcance não apreendi inteiramente, mesmo tendo já desenvolvido certo número de pesquisas de campo e em laboratório.

\footnotetext{
* Maison des Sciences de 1'Homme (Paris, França). Criou e dirigiu o Laboratoire de Psycologie Sociale e da École des Hautes Études en Sciences Sociales (Paris, França). Criou o Laboratoire Européen de Psycologie Sociale na Maison des Sciences de 1'Homme.
}

Tradução de Ana Liési Thurler, do original Les Gitans entre persécution et émancipation.

Artigo recebido em 4 out. 2009 e aprovado em 23 out. 2009. 


\section{Inícios de uma pesquisa}

Há uns vinte e cinco anos, poucos entre nós teriam previsto a queda dos regimes comunistas e o declínio da doutrina dos movimentos de massa, que eram nosso sentido e o sentido da história. Desde então, novas forças políticas e ideológicas tomaram seu lugar e novos Estados, novos povos têm se afirmado e, em muitos continentes, vem se colocando a questão das minorias. O sentido do passado histórico não é um dom solitário, é um fenômeno social. Cícero adverte: "como tudo teria sido diferente (...) se eles tivessem sido vitoriosos diante da vida, esses que alcançaram a vitória na morte". ${ }^{2}$ Compartilhei essa derrota durante os anos de perseguição e guerra. E, talvez, até poderia continuar a manter um relativo silêncio se, após a queda do comunismo, não tivesse observado se multiplicarem as perseguições aos ciganos. Não tenho dúvida de que meu conhecimento e minha familiaridade, desde a infância, com a vida dos ciganos me obrigaram a redescobrir as perseguições e as humilhações, tudo que tanto gostaríamos de esquecer. E, vocês sabem, o que retorna do passado marca-nos e leva-nos a agir prontamente, na esperança de evitar eternas repetições de um mundo familiar.

Comecei por apresentar, na reunião de sociólogos europeus em Amalfi em 1995, uma comunicação sobre a "face nômade" das minorias. Depois, entusiasmado pelas reações de meus colegas, iniciei uma pesquisa no Laboratório Europeu de Psicologia Social. Juan Perez, professor em Valença, apaixonado por esse povo, desde o início encorajou essa pesquisa. Meu objetivo aqui não é retornar aos resultados desse estudo, mas de apresentar-lhes algumas reflexões sobre as possibilidades de nossa teoria das Representações Sociais e, assim, contribuir para o estudo das interações entre uma minoria discriminada e uma maioria discriminadora - em síntese, sobre os preconceitos e as relações entre grupos. Enfim, lançar uma luz nova sobre um fenômeno tão antigo, ao qual um grande número de pesquisas em Psicologia Social se dedica. 
Primo Levi (1987, p. 189) tem razão ao escrever que, "pelo fato de explicarmos os fenômenos ligados aos preconceitos e à intolerância de múltiplas formas e não de um só modo, isso não significa serem essas explicações efetivamente numerosas, mas que a explicação, a motivação completa ainda não foi encontrada." ${ }^{3}$ Não é, pois, a crítica a essas excessivas teorias que me parece questionável, mas o fato de suas motivações haverem sido colocadas acima de qualquer crítica.

\section{Destaques críticos e sugestões criticáveis}

De uma parte, se considera que o preconceito é uma forma distinta do pensamento, ou, como afirma Allport (1966, p, 170), "os processos cognitivos de pessoas preconceituosas são, em geral, diferentes dos processos cognitivos de pessoas tolerantes". ${ }^{4}$ Para sermos mais precisos, podemos aceitar a idéia da psicologia das massas de que as distorções, as simplificações atribuídas aos preconceitos são aspectos do pensamento normal dos homens, com a condição de lembrar que, com uma origem histórica, há uma “normalidade do pré-julgamento" (Gadamer, 1995).

A noção de "preconceito", lançada pela Revolução Francesa, remete à de crença e de senso comum, a toda forma de pensamento que não é produto da razão ou que não o é mais, sem implicar, por isso, uma incapacidade de reflexão ou a escolha normal de um preconceito irrefletido. "Preconceito", escreve o filósofo inglês Williams, é uma palavra poderosa e ambígua, como são suas relações com a teoria. Desempenhou um grande papel na tradição cartesiana, para a qual toda crença é um preconceito sem fundamento. Nesse sentido, tudo é "preconceito", tanto na ciência quanto na ética. Em sentido mais restrito, "preconceito" designa toda crença mantida por ausência de reflexão (Williams, 1985, p. 29). Podemos colocar em dúvida o fato de os homens terem propensão ao preconceito, para explicar as relações entre os indivíduos e, sobretudo, entre os grupos. 
Por outro lado, um segundo tema concernente à motivação cognitiva natural do preconceito reencontrou uma grande audiência e suscitou numerosos estudos. Trata-se do processo de categorização social como um processo adaptativo e funcional, suscetível de organizar e simplificar a massa dos estímulos sociais, de modo que a simples categorização em grupos de estímulos físicos e sociais exagera a similitude no interior de uma categoria e a diferença entre categorias (Tajfel, 1978). E sempre reencontramos no coração desse processo uma distorção cognitiva ou perceptiva, tornando coerente e demasiadamente simples nosso conhecimento das pessoas e do mundo social (Billig, 1986). Eu precisaria de muito tempo para discutir essa teoria e a tendência da Psicologia Social em exagerar a importância do pensamento abstrato e a coerência racional de nosso mundo social. Sabemos que Aristóteles e outros grandes pensadores não chegaram a estabelecer um verdadeiro corte entre as categorias lógicas e as categorias metafóricas do imaginário e da linguagem (Lloyd, 1990, p. 25).

Não quero multiplicar os exemplos para nos convencer que a existência milenar de grupos discriminados, perseguidos não pode derivar de modo tão claro e coerente de um pequeno número de processos cognitivos. Também não quero multiplicar os exemplos para nos convencer que, quando falamos de um grupo semelhante, representamos um grupo humano e quando falamos de um grupo diferente, perseguido, representamos um grupo "animal", não humano. Ao concluir, em 1938, sua crítica aos Protocolos dos Sábios de Sião, Pierre Charles (2009, p. 6), jesuíta de Louvain, lembrava que

jamais os homens faltam com a lógica. Eles são excessivamente, irresistivelmente lógicos... a lógica trabalha por meio de tudo e só raramente se preocupa em se adaptar ao real... Mas o ódio é como a lendária túnica de Djanira, da qual Hércules jamais se desembaraçaria. Ódios são o tesouro que o homem guarda ferozmente e maltrata com furor aqueles que tentam roubá-lo. ${ }^{5}$ 
Sem querer abordar um domínio extremamente vasto para o espaço concedido a este artigo, me contentarei em lembrar-lhes a experiência de Milgram (1974). Sem dúvida vocês sabem que seu plano de fundo é o genocídio e, sobretudo, a personalidade de seus mentores, notadamente Eichmann, cujo processo ocorria na mesma época. Não sei se essa experiência ainda faz parte da literatura especializada. Ela ilustra o fato de que uma pessoa, como você e eu, obedece a uma autoridade que lhe manda dar choques elétricos em desconhecidos. E atendemos sem levar em conta nem nossa própria liberdade de resistir, nem o sofrimento do outro. É o melhor exemplo em laboratório, da moral da obrigação, resumida na expressão familiar "você deve". O primeiro livro que enfrentou sociologicamente o racismo como questão ético-histórica foi publicado em 1989 pelo sociólogo Bauman, com o título Modernity and the Holocaust. Esse autor recusa firmemente a interpretação de psicólogos e sociólogos que invocam tipos de personalidade - por exemplo, autoritária -, ou estereótipos, para explicar esse fenômeno da obediência extrema. Bauman nos mostra até que ponto o Holocausto resulta, ao contrário, da tendência profunda das sociedades modernas a racionalizar, por meio da ciência e da burocracia, as relações entre os homens e a proteger decisões de peritos da interferência dos valores morais ou religiosos. Quanto mais se aperfeiçoam esses métodos ditos racionais, mais se tornam plausíveis os fins que justificam os sofrimentos infligidos aos outros, sem remorsos nem dores. Com a ausência de uma consciência moral ou religiosa viva, não se resiste a deveres injustos impostos pela autoridade e se age indiferente ao destino dos outros. Isso explica também, segundo Bauman, que nas situações ilustradas pelas experiências de Milgram, uma pessoa infligira, sem vergonha nem grandes arrependimentos, a outra pessoa, desconhecida, choques elétricos. Podemos, como ele escreve, "causar sofrimento e permanecer os mesmos". ${ }^{6}$

$\mathrm{Na}$ época em que ele prosseguia com suas experiências, em 1963, Milgram teve oportunidade de ler o livro de Hannah Arendt 
(1963), intitulado Eichmann à Jérusalem: rapport pour la banalité du mal. Justa ou injustamente, essa noção de "banalidade do mal" lhe parecia corresponder ao que ele observava no laboratório. Tudo se passava como se a autoridade tivesse oportunidade de revelar uma vilania presente na maioria dos homens. Mas não era isso que queria dizer Hannah Arendt. Nem o que havia compreendido Bauman, que a cita frequentemente. Ela também se referia à burocracia e pensava que, em todo sistema burocrático, deslocar as responsabilidades emerge da rotina cotidiana. Se quisermos definir a burocracia em termos de ciência política, isto é, como uma forma de governo, o governo das repartições em oposição ao governo dos homens, de um homem, de alguns ou de uma multidão —, a burocracia é governo de ninguém. Por essa razão, talvez ela seja, a mais cruel forma de poder (Arendt, 2009, p. 73). Evocando, entretanto, os anos sombrios vividos na Alemanha, ela invoca a ausência de uma preparação moral e, mesmo, o pouco interesse pelos problemas morais e escreve:

Minha formação intelectual começou em uma atmosfera em que ninguém dava muita atenção às questões morais. Crescemos com o pressuposto de que a conduta moral se compreende por si só. Ainda me lembro muito bem o que eu pensava, quando muito jovem, sobre a retidão moral, o que, em geral, chamamos caráter: toda insistência sobre tal virtude me parecia filistéia, porque também isso, pensávamos, seria tudo natural e sem grande importância. Isso não seria uma qualidade decisiva para avaliar uma dada pessoa por exemplo. Seguramente, cada vez que éramos confrontados com uma fraqueza moral, uma falta de firmeza ou de lealdade, à quase automática capitulação sob a pressão da opinião pública, particularmente... Não tínhamos nenhuma idéia da gravidade dessas coisas e de onde nos conduziriam" (Arendt, 2009, p. 63). ${ }^{7}$

Toda sociedade que classifica os homens e separa os grupos autóctones dos grupos "estrangeiros" inclui um sistema de crenças, religiosas ou outras. Suas representações obedecem a uma norma que dá a seus atos um sentido ético. Esses atos não são cometidos por 
criminosos ou loucos, mas por pessoas que sabem o que é permitido ou proibido, qual é a diferença entre o bem e o mal. Seja na América do Sul ou na América do Norte, a destruição dos indígenas foi feita por homens que guardavam fortemente o mandamento "não matarás" e que discriminavam claramente entre homens que se pode matar e aqueles que se deve matar. Nesse sentido, foi a morte que separou o grupo dos semelhantes do grupo dos diferentes. Por isso creio que a Psicologia Social não é fiel à realidade quando separa julgamentos de fato e julgamentos de valor ou, o mais lastimável, quando os confunde.

É certo que poderíamos colocar questões sobre a pertinência dessas observações concernentes aos judeus, uma vez que nossa pesquisa era consagrada aos ciganos. Mas, de uma parte, há o fato de que estes foram igualmente deportados para campos de concentração. E também há certo parentesco de destino, assim descrito por Bauman $\left(1989\right.$, p. 34): ${ }^{8}$

Um dos aspectos mais impressionantes da diáspora judaica foi a duração do tempo histórico, contínuo, em que "esses estrangeiros particulares" entre nós mantiveram duplamente sua separação: da continuidade diacrônica e da autoidentidade sincrônica. Ao contrário da maioria de outros casos de assentamentos, reaçõeslimite à presença judaica tiveram tempo suficiente para se institucionalizarem como rituais codificados, com capacidade de auto-reprodução, os quais, por sua vez, reforçaram a resiliência à separação. Outra característica peculiar da diáspora judaica foi a universalidade do desarraigamento, uma condição que os judeus dividiram somente com os ciganos. ${ }^{9}$

$\mathrm{O}$ que quer que isso seja, e sem querer fazer uma teoria da questão histórico-ética do racismo, me é necessário extrair uma de suas consequências. Em resumo, ela justifica as críticas de Lewin contra a tendência a classificar grupos e a defini-los pela diferença ou pela similitude entre seus membros. Como se brancos e negros, mulheres e homens, estrangeiros e autóctones formassem grupos 
que, face a face ou lado a lado, permanecessem fechados uns em relação aos outros, como se nada compartilhassem do mundo em que vivem. Ora, é evidente que eles compartilham alguma coisa. Toda vida coletiva pressupõe interdependência e interação. E escreve:

Não é a similitude ou a não-similitude que decide se indivíduos pertencem ao mesmo grupo, mas as interações sociais ou outros tipos de interdependência. Um grupo é melhor definido como uma dinâmica baseada em interdependência do que em similitude. ${ }^{10}$

Se aprofundarmos essas questões, constataremos que se trata da interdependência real ou simbólica entre maioria e minoria (Guillaumin, 2002). É uma relação assimétrica que nos permite melhor compreender a relação entre uma população "hospedeira" e uma população "estrangeira" que, queiramos ou não, compartilham o mesmo destino. Duas coisas estão aqui implicadas. Em primeiro lugar, essa relação assimétrica entre a maioria e a minoria raramente se define por meio de conflito. Em segundo lugar, sua verdadeira finalidade não é a discriminação ou a exclusão, mas a perseguição. É sabido que, na Europa há dez séculos, foram criadas instituições com o objetivo de permitir à maioria perseguir a minoria por meio de julgamentos arbitrários, exílio, humilhação, e assim por diante (Moore, 1991). E a experiência psíquica fundamental é ser corpo e alma à mercê do outro. É nesse nível humano certamente mais profundo, negligenciado pela Psicologia Social, que se compreende e se situa o destino de uma minoria. Todos os romances de Faulkner são consagrados à miséria de negros perseguidos por brancos no sul dos Estados Unidos e o fracasso a que estão condenados - uns e outros -, apesar dos esforços que fazem para escapar da condição de vítima ou mesmo, algumas vezes, de perseguidor. Daqui extraio uma conclusão pessoal. Se essa relação entre maioria e minoria é, no fundo, uma relação de perseguidor e perseguido, compreendemos melhor, então, a dimensão paranóica do racismo. Precisamente porque todo julgamento de acusação, sem qualquer crime ou pecado cometido, suscita a mesma reação de pânico ou de hostilidade, 
como se houvessem realmente sido cometidos tais crimes. Como explicar que qualquer argumento ou observação racional não tem quase nenhum efeito sobre o racismo? Meu julgamento é, talvez, subjetivo. Eu ficaria feliz se assim for.

\section{Os preconceitos dos cientistas e as representações das sociedades}

O ponto de partida das reflexões que se seguirão é que estereótipos - categorias discriminando grupos em brancos e negros, cristãos e judeus, franceses e alemães, indígenas e espanhóis, ciganos e romenos, e a lista é muito longa - não constituem uma classe autônoma de julgamentos ou de imagens que choquem a razão. Em suma, um modo de conhecimento com a função de opor os "semelhantes" preferidos aos "diferentes" desprezíveis, distinguir aqueles que não são como nós. As consequências nos são demasiadamente familiares, para evocá-las ainda uma vez. Os sofrimentos não são argumento, mas sintomas da verdade. Se formos além dos estereótipos ou dos preconceitos, descobriremos sob eles correntes do conhecimento e fórmulas do senso comum, conjuntos de crenças profundamente enraizadas na vida coletiva, mesmo em uma nação moderna. É um efeito, constata Taguieff, na introdução do livro de Voegelin, Race et Etat:

Voegelin estabelece claramente que os teóricos racialistas não podem se restringir a classificações biológicas. Seu projeto de elaborar uma concepção do mundo os conduz sempre a ultrapassar os limites da antropologia física para se dedicarem à produção de psicologias sociais fantasiosas ou simplesmente refletindo "a sabedoria das nações". Assim, arbitrariamente atribuem-se à "raça nórdica" as características morais ou "espirituais", supostas próprias dela, como a busca de objetivos de longo prazo, "o amor ao mar", "a reserva aristocrática", a "sinceridade" e a "pureza", "o sentido da natureza" e, com certeza, a audácia nórdica. (Taguieff, 1933, p. 85). 
Seria mais sábio, mais prudente basear nossas análises em classificações, atos cognitivos feitos habitualmente pelos homens, do que insistir em uma questão histórico-crítica, razão desses atos. Entretanto, essa questão tem o grande interesse de colocar em evidência o sentido da comunidade de destino de uma minoria que vive à mercê da maioria e pode tornar-se o bode expiatório e se ver desqualificada para levar uma vida coletiva, inapta a existir plenamente. Essa questão mostra porque os preconceitos não podem resultar de uma tendência dos indivíduos "para formar generalizações, conceitos, categorias, cujos conteúdos representam uma hipersimplificação de seu mundo de experiência" (Allport, 1966, p. 21). ${ }^{11}$ Porque não somente essa coexistência das minorias e das maiorias é, muitas vezes, secular, mas se apóia também em teorias do senso comum sobre a natureza humana, sobre mitos e tradições, portanto, sobre uma memória coletiva, transmitida de geração em geração. Lewin (1948, p. 164) escreveu:

É bom compreender, que toda minoria não-privilegiada é mantida unida não só por forças de coesão entre seus membros, mas também pela fronteira que a maioria constrói contra a passagem de indivíduos da minoria para a maioria... Há minorias mantidas unidas, quase inteiramente, por um muro. ${ }^{12}$

Conhecemos os muros de guetos, as fronteiras de bairros reservados aos negros e aos chineses, como Harlem e Chinatown em New York e assim por diante. Tais muros não se sustentariam por tanto tempo, se não fossem mantidos por muros psíquicos ou sociais de crenças, estigmas linguísticos, etc. Em resumo, pelas representações sociais que variam segundo as circunstâncias, mas guardam um ar familiar ao longo da história. Moralmente falando, isso é suficiente para reconhecer o que é justo e o que é injusto, mas também, como os indivíduos da experiência de Milgram, para praticar o injusto e não se inquietar com o justo.

Esse lapso de reflexividade explica porque toda minoria é sempre considerada culpada antes de ser julgada. Em resumo, o 
veredito é conhecido antes do processo. Assim, os pecados ou os crimes não são definidos como transgressão da lei, atos associais, mas como tendências inerentes, portanto naturais, da minoria. Geralmente, o que é considerado verdade do grupo aplica-se aos indivíduos julgados como encarnando as "qualidades" do grupo, de modo mais visível e concreto.

Finalmente podemos evocar os processos fundamentais das representações sociais: a objetivação e a ancoragem. Mais concretamente, tudo se ordena na representação social a partir de um nó figurativo que, de algum modo, condensa todas as imagens, todas as noções ou os julgamentos que um grupo ou uma sociedade gera ao longo do tempo. Nada distingue melhor a minoria do que o nó figurativo de sua representação articulada em torno da temática nômade/sedentário, tão fundamental quanto a temática direita/ esquerda na representação social dos partidos políticos. Pesquisando, constatamos que o nó figurativo, há muitos séculos, não variou. James Joyce dizia à época da ascensão de Hitler ao poder: " $O$ antisemitismo é o preconceito mais fácil de provar". ${ }^{13}$ Sem dúvida, pois o nó figurativo da representação social que inclui o tema da errância não variou há mais de dois mil anos. E, sendo impossível negar que essa relação entre maioria e minoria exige provas a pesquisar e preservar em uma memória coletiva, é surpreendente que não figure na maior parte das teorias sobre o racismo ou os preconceitos.

Infelizmente o tempo é demasiadamente curto para nos determos mais longamente sobre o processo de objetivação da representação social dos ciganos, que apreendemos na pesquisa sobre essa minoria hoje chamada Roms en Europe. ${ }^{14}$ Sempre que o nó figurativo é associado a um conceito e a uma imagem dessa minoria e se reproduz em tudo que é dito e pensado a seu respeito, esse nó figurativo é expresso em uma série de temas emblemáticos. Primeiramente, o tema do puro e do impuro (limpos/sujos), definindo a presença da minoria como uma anomalia no interior da população 
autóctone. De certa forma, ela se materializa na época em que a inquisição espanhola introduziu o conceito racial de "pureza do sangue". À semelhança dos judeus, os ciganos são considerados "nação daninha de mendigos e ociosos", quase um elemento satânico da sociedade. Dado que eram cristãos, não foram expulsos da Espanha, mas apartados em espaços dos quais, por impuros, lhes era proibido sair. Mesmo se já não se evoque o sangue, a pureza e a impureza se concretizam no estabelecimento dos territórios de residência em relação à maioria.

O segundo tema emblemático é o dos estigmas que marcam quase todas as minorias e seus contrastes com a maioria. Em um nível mais profundo da relação entre maioria e minoria, cada estigma ganha o sentido de uma resposta à questão que os espanhóis se colocaram relativamente aos indígenas da América: são ou não humanos? Tudo se passa como se o estigma não fosse justamente uma marca da minoria, mas um modo de pensá-la que se substitui ou torna impossível pensá-la simbolicamente (Moscovici, 2002). Não há distinção essencial entre os estigmas naturais e os estigmas ditos artificiais. Uns e outros distinguem seu portador como pertencente a uma minoria perseguida e marcada pela infâmia. Representados como músicos ou criminosos, os ciganos fundem-nos na mesma representação social marcada pela infâmia. Nietzsche escreveu: "Grava-se algo a ferro em brasa para fixá-lo na memória. Somente o que faz mal é conservado pela memória." 15 Na memória dos estigmatizados, evidentemente.

Todo mundo sabe que, apesar da lei, os ciganos não têm o direito de se fixar em lugar algum, nem em um trem, nem em uma estação, e que os espaços onde lhes é admitido morar, frequentemente, lhes são reservados em uma cidade, por tempo limitado. Evidentemente, a segregação é bem pior quando essas restrições se exprimem por meio de violências contra seus vilarejos e bairros. O tema emblemático do senso comum, que justifica tais ações, é a proibição do contato. Quaisquer que sejam as razões, 
trata-se de um interdito arcaico e, sem dúvida, universal (Moscovici, 1988) . Por toda parte se colocam obstáculos a aproximações na vida cotidiana, objetivando comportamentos de rejeição, de desagrado ou de medo em relação à minoria. Denise Jodelet (1989) analisou, finamente, esse comportamento em uma situação em que a maioria coabita com a minoria, permanentemente. E em uma experiência realizada na Espanha, mostramos uma ontologização dos ciganos com uma espécie animal, como um método da maioria para acentuar o tabu do contato com a minoria (Pérez, Moscovici, e Chulvi, 2002). Não é surpreendente que essas temáticas estruturem a representação social e precedam, para falar metaforicamente, o nascimento das relações entre minorias e maiorias, no contexto de perseguição étnica, religiosa, etc. Para além do que vivi e aprendi nos estudos antropológicos e históricos, tenho a convicção de que essas pesquisas com Juan Pérez deram uma idéia mais precisa desse muro de que fala Lewin, do modo como as maiorias levantamno em torno das minorias, e também da grande dificuldade que experimentamos para nos livrar de dominações raciais, étnicas, religiosas, seus corsi et ricordi ${ }^{16}$ durante a história. Se considerarmos as raras épocas luminosas em que os homens puderam dizer "nisso não devo pensar", "isso não devo fazer", antes de ceder, julgamos melhor a compulsão de perseguição do semelhante pelo semelhante. Talvez seja esse o sentido do "Conhece-te a ti mesmo" que os gregos inscreveram no templo de Apolo, em Atenas. Nessas observações não há qualquer intenção crítica nem relação às teorias, nem em relação aos pesquisadores que têm estudado esses fenômenos há muito tempo. Respeito a competência e a capacidade de invenção deles. Tudo o que posso dizer agora é que o desejo de justificar a extensão da teoria das representações sociais no campo da veneranda pesquisa me incitou a falar desse grupo que conheço desde sempre.

\section{A metamorfose das minorias}

Tratarei a seguir do segundo processo, a ancoragem, expressando a difusão de uma representação social e sua transposição 
na língua, nas imagens ou nas situações típicas de um novo meio social. Há, sem dúvida, um elemento mimético nesse processo, pois não se pode interagir com um outro grupo, sendo esse uma minoria, sem aí encontrar alguma coisa de - ou por - si mesmo. Billig (1986) insistiu na singularidade desse processo:

Há uma diferença crucial entre o approach cognitivo e aquele [que] tende a examinar categorizações em termos de um funcionamento individual. Por contraste, representações sociais analisam o funcionamento social que é representado como funcionamento social, ancorando o que é representado em um objeto social, uma ancoragem de tensões individuais na tradição cultural do grupo, no desenvolvimento dessas tradições. Nesse sentido, as representações estão enraizadas na vida do grupo. ${ }^{17}$

Ocorre, então, que a maioria trabalha para exprimir seus fins, suas ações simbólicas nas relações com a minoria, se apoiando sobre seu próprio passado, suas tradições e comunicando-as aos outros. Em resumo, a ancoragem nos familiariza com uma representação social nova e nos remete ao que já era familiar em uma antiga representação. É o que acontece também na tradução e reprodução das obras de arte. Se há preconceito é porque a toda ação, a todo julgamento novo corresponde, simultaneamente, um sentido antigo.

Com certeza vocês se lembram da noção de nó figurativo presente em toda representação social, associando conceitos e imagens ou vice-versa, definindo uma temática. Por exemplo, direita/esquerda no campo político ou sagrado/profano no campo religioso. Nada exprime melhor a singularidade da minoria cigana do que a temática nômade/sedentário. Mais concretamente, isso condensa duas faces de seu nomadismo: uma face positiva - a dos ciganos praticando uma profissão, sendo as mais populares as de músico ou saltimbanco - e uma face negativa - a dos ciganos mendicantes ou delinquentes, levando uma vida precária e fora da lei. E a constatação que se pode alcançar por meio de leis históricas é ainda mais impressionante: o nó figurativo da representação social 
deles não mudou significativamente há quatro séculos (Garo, 2009). Por essa razão escolhi um exemplo histórico para ilustrar, ao mesmo tempo, uma persistência de sua representação social e uma variante que a prolongou na sociedade moderna.

A história se desenrola na França, em meado do século XIX, na aurora da sociedade burguesa moderna, que fixou a população em suas fábricas, administrações e comércios, com uma maioria social e política sedentária e desejando assim se ver. Para distinguir o tipo normal e a representação da vida sedentária como forma de vida da maioria, é preciso inventar um contra-tipo de uma minoria errante e flutuante, nos interstícios da sociedade. A invenção consciente ou inconsciente da representação de tal minoria não é nova, mas não é necessário insistir nisso. Em todo caso, essa minoria era ou deveria ser constituída por deslocados, malogrados, estrangeiros, exilados, potenciais criminosos, todos indiferentes ou hostis à ordem social. Sem dúvida, vocês ouviram falar de boemia, de vida de boêmio. Ora, esse substantivo foi suficiente para ancorar a representação dos ciganos e difundi-la no conjunto da sociedade, pois seu nome era originário da Boêmia.

Foi em Paris, segundo Walter Benjamin, então a capital do mundo, que esses boêmios plantaram sua sociedade, com contornos mal definidos, mesclados, como a sociedade dos ciganos, no entanto, bem identificáveis, com seus cafés, tavernas, ateliês, sede de associações, revolucionários, jornais e suas gírias. O grande sociólogo político da época, Robert Michels, se refere não somente aos escritores, mas igualmente aos boêmios, como uma "classe de párias" ou de "ciganos de espírito". Observa-se que o nó figurativo da representação social dos ciganos penetra e torna-se nó de uma representação social dos não-ciganos, referidos como "gadgé", ${ }^{18}$ que, até certo ponto, opera sobre sua história, modo de vida e forma de se conduzir. Ora, não é duvidoso que a representação da boemia, com os ciganos de plano de fundo, criou a boemia "de carne e osso". 
Estou persuadido disso, mas seria necessário um trabalho mais sério para provar.

Mas o mais significativo é reencontrar as duas faces da representação social, a face positiva de um lado, com os artistas inovadores e os músicos, e, de outro lado, essa face negativa, com os revolucionários, os anarquistas que refluem para Paris, se reencontram em seus cafés ou sedes de seu partido, a liga comunista, para conspirar contra seu governo - russo, italiano, alemão, que os exilou e os obrigou a fugir. Eles vêm engrossar as fileiras, observam Marx e Engels, "desse meio social que em Paris chamam a boemia", nas tavernas dos mercadores de vinho, esses locais de encontro de conspiradores - os boêmios revolucionários de origem proletária, vigiados pela polícia francesa. Destaca-se o modo como são reconhecidos: de uma parte, os conspiradores de ocasião que levam uma vida profissional normal, na maioria sedentária; de outra parte parte, os conspiradores de profissão que consagram toda a existência à conspiração, entre os quais Louis-Auguste Blanqui era o modelo. Esses são os nômades modernos que agiam fora da lei e contra a lei que Walter Benjamin cita abundantemente em seu livro inacabado sobre Paris, capital do século XIX. Certo, meditaremos sobre esses textos um século mais tarde, mas também sobre sua experiência do exílio, em suas digressões sobre a boemia e esses "artistas da conspiração", que formam "o exército de reserva da intelligentsia burguesa", nas palavras de W. Benjamin. Após terem participado das conspirações do exército desde seus inícios, eles participam das insurreições do mundo operário. Tornam-se conspiradores "profissionais". Em um sentido, isso faz deles precursores dos revolucionários e anarquistas (Traverso, 2004).

Peço-lhes perdão por haver escolhido esse exemplo, mas a psicologia social não é estranha à história de uma minoria emergente - artistas, proletários, revolucionários -, reencontrada por meio dos temas e figuras de uma minoria rejeitada mas familiar, que serve de ponto de ancoragem. Podemos acrescentar, a título ilustrativo, 
o exemplo admirável e célebre de Marx, pertencente a essa boemia de exilados e revolucionários. Por exemplo, sua imagem. Em 1922, Antonio Gramsci descreveu-o nas páginas de um conhecido jornal como "um homem, ao mesmo tempo, da ciência e da ação, um crítico e um demagogo sectário e adepto, ao mesmo tempo, de Deus e do diabo, Apolo e o rei dos ciganos" (Traverso, 2004, p. 51). Ele deixa de dizer - mas é melhor fazê-lo - que foi a partir da representação social da minoria cigana ancorada na França, como exemplo de errância e de uma vida fora da lei, que a representação da minoria boêmia se forma e não por contatos com os ciganos mesmos, que se continuou a tratar como seres miseráveis e perigosos. Temos testemunho disso em Flaubert e em outros escritores escandalizados da época.

Falando-lhes desses grandes acontecimentos de outrora, em que a emergência da boemia foi um deles, os "preconceitos" me aparecem como os Ready made do pintor Duchamp, esse artista que, assinando seu nome sobre objetos usuais, um urinol ou uma cadeira, os desloca para o mundo estético como objetos de arte. Não há necessidade de trabalhá-los a partir de um material escolhido - ferro ou cerâmica -, mas justamente de escolhê-los, de acrescentar-lhes seu nome, para deslocar o objeto de uma loja ordinária para uma galeria de arte e, com isso, mudar o olhar do público. Talvez nossos preconceitos são Ready made, gestos mentais que transfiguram alguns de nossos julgamentos, colocados em contato por nosso senso comum ou pela ciência de relações com uma minoria. Eis aí uma questão à qual, seguramente, será necessário retornar algum dia para melhor compreender a gênese de representações estranhas, e mesmo violentas, da perseguição aos outros, a partir de nossas representações familiares.

\section{As possibilidades de emancipação}

Herdeiros de uma tradição popular, os ciganos sofreram e sofrem ainda coações, vexações que fundam as representações 
sociais, até lendas forjadas pelas coletividades ou por nações autóctones para se justificar. O sucesso, na Alemanha do darwinismo social e da volkspsicologia no período nazista, metamorfoseou a representação social dos ciganos em representações científicas, com as consequências que sabemos. No fim de 1942, em balanços dos estudos alemães, podíamos ler:

Os resultados de nossa pesquisa científica suscitam primeiramente o maior respeito nos círculos nacionais e internacionais, aprovandoos ou contestando-os. Mas o imprevisível mérito histórico de Adolfo Hitler e de seus homens terá sido de se engajar além da pura pesquisa científica, de forma inovadora e decisiva sobre a via de uma ação eugênica genial no e para o povo alemão. Nele e em seus colaboradores recaem o mérito de ter colocado em prática as teorias e as exigências do pensamento racial nórdico, a luta contra as raças parasitas de sangue estrangeiro como judeus e ciganos, e de ter impedido a reprodução de portadores de doenças hereditárias e de indivíduos hereditariamente inferiores. (Voegelin, 1933, p. 25) ${ }^{19}$

Não comentei esse texto que testemunha a ontologização das representações sociais de ciganos e de sua destruição física. Apesar das perseguições que os ciganos sofreram durante ou depois da segunda guerra mundial, o momento em que começamos esse estudo representou um ponto de não retorno. A mundialização dos Direitos Humanos e a obrigação de a União Européia criar uma ordem jurídica minoritária tiveram as mesmas consequências para os ciganos e outras minorias. De uma parte, a proteção legal das comunidades ciganas contra as perseguições e as violências pelas quais elas eram atingidas - o que não significa que essas perseguições e essas violências desapareceram. De outra parte, uma presença mais ativa das comunidades ciganas com a criação de associações ou de movimentos que as representam e se engajam na invenção de um futuro comum. Incluindo a idéia de nação em suas representações, por assim dizer, eles mudaram de nome: eles se tornaram os Roms (Garo, 2009). 
Em sua bela tese, Gina Philogène analisou o processo e a significação da escolha de um novo nome "afro-americano" para as comunidades negras nos Estados Unidos. Sintoma de emancipação, a "nominação" é expressão de uma nova referência compartilhada e de uma representação social que lhe corresponde. Putnam e Kripke insistem nos dois aspectos a seguir. De uma parte, um nome é associado a uma "teoria", a uma representação social simplificada. Não é indispensável crer nessa teoria, mas somente estar consciente do fato de que ela está associada a esse nome. Em seguida, a nominação é um processo cognitivo e social. Kripke descreve nestes termos esse processo:

um nome é dado a uma pessoa em um 'batismo' ou em uso inicial com o referente presente. Isso, então, é passado de pessoa a pessoa. Tanto temos sorte ou a cadeia casual, isto é, o ultimo interlocutor da corrente usa o nome com a mesma referência que o primeiro, referência à pessoa "batizada", que é completada com o uso do nome. Nesse caso, a referência ao referente inicial do nome não conhece descrições unicamente especificadoras do referente. (Schwartz, 1977, p. 32). ${ }^{20}$

Sem esforço imaginamos que se o batismo começou, se a denominação Rom aborda sua carreira histórica e política, o destino desse povo não se alterará de um dia para o outro. Quaisquer que sejam os infortúnios das coletividades ciganas, em momento algum elas consideram uma sedentarização permanente e, pode-se supor, uma unificação. A história dos povos europeus testemunha que a emancipação exige inúmeros sacrifícios simbólicos, mais difíceis de suportar que os sacrifícios físicos. E a condição previsível é a criação de uma representação social, sobretudo tratando-se de um povo nômade no meio de povos sedentários. A consciência de pertencimento a uma minoria "nacional", de compartilhar uma língua, o desejo de estudar afirmado pelos Roms e não pelos ciganos é um primeiro passo na direção da emancipação. Entretanto, é importante não perder de vista que a emancipação é um longo processo, pois 
não se forja um destino comum e um destino próprio de hoje para amanhã. Os obstáculos interiores que exigem o sacrifício de uma tradição, até de uma memória coletiva são mais formidáveis do que os obstáculos exteriores, como testemunha a história das nações européias.

A simples coexistência espacial de um grupo de indivíduos não os constituía como povo. Eles não se tornarão um povo pelo simples fato de que teriam uma atividade comum, a agricultura, o comércio ou uma ordem jurídica comum. O que construirá um povo é a "comunidade de consciência", uma visão comum do mundo, uma "mitologia compartilhada". (Voegelin, 1933, p. 255) 21 $^{1}$

A psicologia social se consagrou à separação, à discriminação, de fato, como eu acreditava, na perseguição de uma minoria pela maioria. Mas em nossa época, quando as minorias até então passivas reclamam sua autonomia, tornam-se minorias ativas, o processo de emancipação deveria nos abrir perspectivas mais dinâmicas do que a advertência sobre as mazelas familiares de nosso mundo. Nos momentos mais difíceis de minha vida, lembrei dos últimos versos do poema "Cemitério marinho", de Valéry (1922): 22 "Levanta-se o vento!... Temos que viver!"23

\section{Notas}

1 Ver anais dessa Jornada em Almeida e Jodelet ( 2009).

2 No original: "comme tout aurait été différent [...] s'ils avaient été victorieux devant leur vie, ceux qui ont remporté la victoire dans la mort."

3 No original: "Le fait qu'on n'explique pas d'une seule façon mais de multiples, les phénomènes liés aux préjugés et à l'intolérance, ne signifie pas que les explications sont effectivement nombreuses, mais que l'explication, la motivation complète n'a pas été trouvée." 
4 No original: "the cognitive processes of prejudiced people are in general different from the cognitive processes of tolerant people".

5 No original: "les hommes ne manquent jamais de logique; ils sont effroyablement, irrésistiblement logiques ... la logique travaille à travers tout, ne se souciait que rarement de s'adapter au réel... Mais la haine est comme la tunique légendaire de Déjanire, dont Hercule n'arrivait plus à se débarrasser. Les haines sont, hélas, le trésor que l'homme garde férocement, et il lapide avec rage ceux qui tentent de lui ravir".

6 No original: "cause suffering and remain yourself".

7 No original: "Ma formation intellectuelle a commencé dans une atmosphère où personne ne prêtait beaucoup d'attention aux questions morales, nous étions élevés dans le présupposé : la conduite morale se comprend d'elle-même. Je me rappelle encore assez bien ce que je pensais quand j'étais assez jeune de la rectitude morale que nous appelons en général le caractère : toute une insistance sur une telle vertu me serait apparue comme philistine, parce que cela aussi, pensionsnous, était tout naturel et donc sans grande importance. Ce n'était pas une qualité décisive, par exemple, pour évaluer une personne donnée. Assurément, chaque fois que nous étions confrontés à une faiblesse morale, à un manque de fermeté ou de loyauté, à la curieuse presque automatique capitulation sous la pression, en particulier de l'opinion publique... nous n'avions aucune idée du sérieux de ces choses et de ce à quoi elles conduiraient".

8 Em tradução livre.

9 No original: "A most spectacular distinctive feature of the Jewish Diaspora was the sheer length of historical time through which "these particular foreigners" in our midst retained their separation, both of diachronic continuity and synchronic self-identity. Unlike in the most other cases of resettlement therefore, boundary-clearing responses to the Jewish presence had enough time to institutionalize as codified rituals with an in built self reproducing capacity, which in its turn further reinforced the resilience of the separation. Another peculiar feature of the Jewish Diaspora was the universality of Jewish homelessness, a quality that Jewish shared only with the Gypsies." 
10 No original: "It is not similarity or dissimilarity, that decides whether two individuals belong to the same group, but social interaction or other type of interdependencies. A group is best defined as a dynamic while based on interdependence rather on a similarity".

11 No original: "to form generalizations, concepts, categories, whose contents represents an oversimplification of his world of experience."

12 No original: "It is well to realize that every underprivileged minority group is kept together not only by cohesive forces among its members but also by the boundary which the majority erects against the crossing of an individual from the minority to the majority... There are minorities which are kept together almost entirely by such a wall."

13 No original: "L'antisémitisme est le préjugé le plus facile à prouver".

14 Ciganos na Europa, remetendo à romani, complexo de dialetos falados por ciganos de diferentes países e que, genealogicamente, pertencem à família indo-européia.

15 No original : "On grave quelque chose au fer rouge pour le fixer dans la mémoire; seul ce qui fait mal est conservé par la mémoire."

16 NT: Cursos e memórias.

17 No original: "There is a crucial difference between the cognitive approach and that cognitive... tend to view categorizations in terms of individual functioning. By contrast, social representations examine the social functioning that is represented as a social functioning anchoring what is represented in a social object and an anchoring draws individual into the cultural tradition of the group, the developing of these traditions. On this way representations are rooted in the life of the group."

18 NT: Derivação de gadget, objeto divertido, mais ou menos fútil; gadgets idiots (Robert Micro.... 1998).

19 No original: "Les résultats de notre recherche scientifique suscitaient auparavant le plus grand respect dans les cercles nationaux et internationaux, qu'on les approuvait ou qu'on les contestait. Mais 
l'imprévisible mérite historique d'Adolphe Hitler et de ses hommes aura été de s'engager au-delà de la pure recherche scientifique, de façon novatrice et décisive sur la voie d'une action eugénique géniale dans et par le peuple allemand. C'est à lui et à ses collaborateurs que revient le mérite d'avoir mis en pratique les théories et les exigences de la pensée raciale nordique, la lutte contre les races parasites de sang étranger comme celles des Juifs et des Tziganes, et d'avoir empêché la reproduction des porteurs des maladies héréditaires et d'individus héréditairement inférieurs".

20 No original: "A name is given to a person in a "baptism " or an initial use with the referent présent. It is then handed on from speaker to speaker. As long we have the right sort of causal chain, that is, as long as the later speaker in the chain intend to use the name with the same reference as the earlier, reference to the person 'baptized' is accomplished by use of the name. In this way reference to the initial referentof the name knows no descriptions uniquely specifying the referent."

21 No original: "La simple coexistence spatiale d'un groupe d'individus ne les constituerait pas pour autant en peuple; et ils ne deviendraient pas un peuple du simple fait qu'ils auraient une activité commune, l'agriculture, le commerce ou un ordre juridique commun. Ce qui construirait un peuple, c'est la "communauté de conscience”, une vision commune du monde, une "mythologie partagée".

22 NT: Título original Le cimetière marin, do poeta francês Paul Valéry (1871-1945). O Mar Morto e o Mar Vermelho têm sido designados cemitérios marinhos.

23 No original: "le vent se lève !.. .Il faut tenter de vivre!"

The gypsies between persecution and emancipation

Abstract: Every society that classifies mankind and separates the autochthonous groups from the "foreign" groups includes a system 
of beliefs, being it religious or of another kind. Their representations obey a norm that gives their actions an ethical sense. Those actions are not committed by criminals or crazy people, but by the ones who know what it is allowed or forbidden, or what the difference between good and evil is. The starting point of the presented reflections is that stereotypes categories which discriminate groups in whites and blacks, Christians and Jews, Frenchmen and Germans, indigenous and Spaniards, gypsies and Rumanians etc. constitute, in short, a way of knowledge with the function of opposing the favorite "fellow creatures" to the despicable "different ones", to distinguish those who are not like us.

Keywords: prejudice; gypsies; social representations; social psychology.

\section{Referências bibliográficas}

ALLPORT, G.W. The nature of prejudice. Cambridge, Mass: AddisonWesley, 1966.

ALMEIDA, A. M. O.; JODELET, D. (Eds.). Representações sociais: interdisciplinaridade e diversidade de paradigmas. Brasília: Thesaurus, 2009.

ARENDT, H. Eichmann à Jérusalem: rapport sur la banalité du mal, Paris. Gallimard, 1966. [Tradução francesa de Eichmann in Jerusalem: a report on the banality of evil. New York: The Vinking Press, $1963]$. . Responsabilité et jugement. Paris: Payot, 2009.

BAUMAN, Z. Modernity and the holocaust. Cambridge: Polity Press, 1989.

BILLIG, M. Prejudices, categorization and particularization. European Journal of Social Psychology, n. 15, p. 79-103, 1986.

CHARLES, P. Face aux Protocoles de Sion. In: OLENDER, M. (Ed.). La chasse aux évidences. Paris: Galade, 2009. 
GADAMER, H. G. Langage et vérité. Paris: Gallimard, 1995

GARO, M. Les Roms, une nation en devenir. Paris: Sylepse, 2009.

GUILLAUMIN, C. L'idéologie raciste: genese et langage actuel. Paris: Gallimard, 2002.

JODELET, D. Folies et représentations sociales. Paris: Presses Universitaires de France, 1989. [Tradução em português: Loucuras e representações sociais. Petrópolis: Vozes, 2005].

LEVI, Primo. Si c'est un homme. Paris: Julliard, 1987.

LEWIN, Kurt. Resolving social conflicts: selected papers on group dynamics. New York: Harper and Row, 1948.

LLOYD, G. E. R. Demystifying mentalities. Cambridge: Cambridge University Press, 1990.

MILGRAM, S. Obedience to authority. New York: Harper and Row, 1974.

MOORE, R. I. La persecution. Paris: Les Belles Lettres, 1991

MOSCOVICI, S. La machine à faire des Dieux. Paris: Fayard, 1988.

- Pensée stigmatique et pensée symbolique, deux formes élémentaires de la pensée sociale. In: GARNIER, Catherine (Ed.). Les formes de la pensée sociale. Paris: PUF, 2002.

PÉREZ, J. A.; MOSCOVICI, S.; CHULVI, B. Nature and culture as principles for social classification: anchorage of social representations on ethnical minorities. Revista de Psicología Social, Madrid, v. 17, n. 1, p. 51-67, enero, 2002.

ROBERT micro: dictionnaire de la langue française (le). Paris, 1998.

SCHWARTZ, S. P. (Ed.). Naming, necessity and natural kinds. Ithaca: Cornell University Press, 1977.

TAGUIEFF, P. A. Introduction. In : VOEGELIN, E. Race et Etat. Paris: Vrin, 1933. 
TAJFEL, H. Differentiation between social groups. New York: Academic Press, 1978.

TRAVERSO, E. La pensée dispersée. Paris: Lignes \& Manifestes, 2004.

VALÉRY, P. Charmes. Paris: Gallimard, 1922. (Editions de la NRF).

WILLIAMS, B. L'Ethique et les limites de la philosophie. Paris: Gallimard, 1985. 